\title{
El salmo 59 como base de la interpretación apocalíptico-milenarista de la misión fundadora de los franciscanos en Nueva España
}

\author{
Palabras clave: salmo 59 - franciscanos - evangelización — México - milenarismo \\ apocalíptico.
}

En su Historia de los Indios de la Nueva España Fray Toribio de Motolinía escribe sobre el líder de los Doce apóstoles de México, Martín de Valencia:

\begin{abstract}
Pues preseverando el varón de Dios en sus santos deseos, quísole el Señor visitar y consolar de esta manera: que estando él un noche en maitines en tiempo de adviento, que en el coro se rezaba la cuarta matinada, luego que se comenzaron los maitines comenzó á sentir nueva manera de devoción y mucha consolación en su ánima; y vínole á la memoria la conversión de los infieles; y meditando con esto, los salmos que iba diciendo en muchas partes hallaba entendimientos devotos á este propósito, en especial en aquel salmo que comienza: Eripe me de inimicis meis: y decía el siervo de Dios entre sí: “¡Oh! ¿Y cuándo será esto? ¿Cuándo se cumplirá esta profecía? ¿No sería yo digno de ver este convertimiento, pues ya estamos en la tarde y fin de nuestros días, y en la última edad del mundo?"1
\end{abstract}

A su vez, Jerónimo de Mendieta nos está ofreciendo un relato similar, seguramente basándose en el testimonio recién citado, aunque indicando, como motivo principal del espíritu cristiano de Martín de Valencia, su ferviente deseo de ofrecerse al martirio por la salvación de sus prójimos y la consolación que le llegó de parte del Señor:

Lo cual pasó de esta suerte. Rezando una noche los maitines en el coro y comunidad del monasterio del Hoyo, una feria cuarta en tiempo de Adviento, luego en el principio de ellos comenzó á sentir una devoción interior y á traer en la memoria la conversión de los infieles. Y

${ }^{1}$ T. Motolinía Benavente, "Historia de los indios de la Nueva España", en: J. García Icazbalceta, Colección de documentos para la historia de México, T. I, México, Editorial Porrúa, 2004 [1858-1866], pp. 150-151. 
pensando en esto, en muchos versos de los salmos que iba rezando hallaba entendimientos á este propósito, de que mucho se gozaba su alma y espíritu. Augumentábasele más este deseo en aquel salmo que comienza: Eripe me de inimicis meis, Deus meus, donde dos veses se repite aquel verso, Convertertur ad vesperam, et famen patientur ut canes: convertirse han á la tarde, y padecerán hambre como perros. Y decía hablando consigo mismo " ¿Y cuándo será esto? ¿Cuándo se cumplirá esta profecía? ¿Cuándo será esta tarde? ¿No sería en este tiempo? ¿No sería yo digno de ver este convertimiento, pues ya estamos en las vísperas y fin de nuestros días, y en la última edad del mundo?"²

Ambos fragmentos desde hace mucho tiempo, al lado de otras referencias, han servido para otorgarle a la misión apostólica de los primeros franciscanos un carácter particular y un trasfondo que iba mucho más allá que la ortodoxia de la Orden, profundamente reformada en las dos primeras décadas del siglo XVI. Nos referimos a diferentes ideas adscritas o imputadas a los franciscanos mencionados por tales autores como José Antonio Maravall, John L. Phelan y finalmente el más importante, Georges Baudot ${ }^{3}$. En términos generales se menciona en este contexto ideas tales como: milenarismo apocalíptico, mesianismo, utopismo, fiorismo, savonarolismo, etc. ${ }^{4}$ En cuanto a la reacción frente a este tipo de hipótesis y especulaciones se ha formado una extensa literatura ${ }^{5}$, que vamos a abordar en nuestra monografía dedicada a los Coloquios de 1524 de Fray Bernardino de Sahagún en el capítulo donde tratamos del equipamiento espiritual de los Doce apóstoles de la Nueva España.

En su libro Baudot, haciendo referencia directa a los fragmentos de Motolinía y Mendieta presentados al principio de la presente glosa, comenta con cierta razón que lo que narran ambos cronistas muestra que "la evangelización apareció muy pronto a fray Martín como una imperiosa necesidad dentro de la lógica prolongación de la reforma guadalupana que él promovía y encarnaba"6. Obviamente los dos testimonios de los cronistas muestran a un Valencia que sueña con la misión de la cristianización de los paganos y que incluso, un poco desilusionado en cuanto la posibilidad de convertirse en

2 J. Mendieta, Historia Eclesiástica Indiana, México D.F., Editorial Porrúa, 1993 [1870], p. 73. En el margen de esta página el autor nos indica el número 58 del salmo, lo que nos confirma que el autor recurría a la versión latina de los salmos, la Vulgata, la que proviene de la griega, de la llamada Septuaginta; en las versiones que se basan en el hebreo (texto masorético) el mismo salmo lleva número 59.

${ }^{3}$ Cf. lista de referencias bibliográficas al final del artículo.

${ }^{4}$ Una revisión sumaria de esta problemática la encontramos en M. Andrés Martín, "En torno de las últimas interpretaciones de la primitiva acción evangelizadora en México", en: J. Saranyana et alt. (eds.), Evangelización y teología en América (siglo XVI): X Simposio Internacional de Teología de la Universidad de Navarra, Pamplona, Servicio de Publicaciones de la Universidad de Navarra, 1990, vol. 2, p. 1346.

${ }^{5}$ Mencionemos aquí solamente algunos, más importantes autores: L.L. Canedo, M. Andrés Martín, A. de Zaballa Beascoechea, V. Murillo Gallegos, F. Hubeñak.

${ }^{6}$ G. Baudot, Utopía e Historia en México, Madrid, Espasa-Calpe, 1983 (versión original en francés editada en 1977), p. 95. 
un mártir de la fe cristiana, procuró con la ayuda de Cortés una expedición a China, una empresa frustrada en las circunstancias un poco oscuras ${ }^{7}$.

Hay que mencionar que, si bien la referencia a los fragmentos citados al principio es directa y obvia, sin embargo, Baudot no menciona que las exclamaciones de Valencia (“¿Cuándo se cumplirá esta profecía?”8) guardan relación con el contenido del salmo 59. Lo que nos importa aquí es observar que la referencia citada de Baudot, constituye para él, entre otras ${ }^{9}$, una base para una interpretación de la empresa evangelizadora de los primeros franciscanos en México en términos del milenarismo apocalíptico y mesianismo ${ }^{10}$. No hace

${ }^{7}$ Cf. J. Mendieta, op. cit., p. 594: "Después, visto que no podía conseguir la palma del martirio entre estos indios, porque luego todos ellos sin dificultad alguna recibieron la fe y se subjetaron á la doctrina de la Iglesia, intentó de pasar á la China. Esto fue un año antes de su muerte, que fué el de mil y quinientos y treinta y tres [...]" (véase también pp. 586-588). Observemos de paso que relacionar la idea de la expedición evangelizadora a China con cualquier sentido milenarista resulta ser erróneo. Una versión distinta de esta expedición la que menciona Mendieta encontramos en: F. Chauvet, Franciscanos memorables en México, México, Centro de Estudios Bernardino de Sahagún, 1983, p. 216.

${ }^{8}$ G. Baudot, op. cit., p. 96.

${ }^{9}$ Otra referencia - base para el planteamiento de Baudot es la mención hecha por Motolinía (op. cit., p. 153) y luego repetida de manera un poco anónima por Mendieta (op. cit., p. 199) del supuesto encuentro con cierta Beata que iba a calmar la impaciencia de Valencia en cuanto sus anhelos evangelizadores, profetizándole que sus deseos se cumplirán en un futuro. A este tema vamos a dedicar un artículo aparte, aquí solamente mencionaremos que tanto Baudot, como antes Maravall hablan de la Beata del Barco de Ávila. En el caso de Baudot no se menciona que de hecho se trataba de la famosa Beata de Piedrahita y en el caso de Maravall se plantea la existencia de... dos Beatas.

${ }^{10}$ G. Baudot, op. cit., p. 377. Cf. también G. Baudot, "Las crónicas etnográficas de los evangelizadores franciscanos", en: B. Garza Cuarón, G. Baudot, Historia de la literatura mexicana, México, D.F., Siglo XXI, 1996, p. 293; J. M. Kobayashi, La educación como conquista, México D.F., El Colegio de México, 2002, pp. 138-139. Vale la pena en este lugar citar un fragmento del libro de Cecilia Frost (C. Frost, Este nuevo orbe, México D.F., UNAM, Serie Nuestra América 52, 1996, p. 19): "Todo europeo medianamente culto sabía de la existencia de grandes grupos humanos en Asia y África que a pesar de todos los intentos misionales seguían siendo paganos". No cabe la menor duda que Martín de Valencia recibió una formación que seguramente cumplía con el criterio de un europeo "medianamente culto" y por lo tanto la posibilidad del surgimiento de cualesquiera ilusiones de que la conversión del Nuevo Mundo hubiera completado los supuestos sobre la llegada del fin de los tiempos era prácticamente imposible... Además a medida de los avances del orden colonial en el Nuevo Mundo cada vez más se percataban los religiosos de la existencia de grandes grupos humanos fuera del alcance de los anhelos evangelizadores. La esperanza de la llegada de Jesús Cristo constituía un lugar común en el marco del paradigma cristiano, en cambio ideas milenaristas siempre se colocaban en lo heterodoxo y a veces herético. Esperar entre los Doce este tipo de posturas significa manifestar un desconocimiento total de su perfil espiritual formado a caballo del siglo XV y XVI, perfil que en su versión de la descalcez franciscana rebasaba la observancia, más solía ser combatida por ella... No obstante y como lo muestran autores competentes, justamente de la rigurosa descalcez salieron los miembros de la primera oficial misión evangelizadora en México (cf. las obras de M. Andrés Martín, y también: J. Achmatowicz, "Dwunastu ewangelizatorów Nowej Hiszpanii (przyczynek do historii duchowego podboju Meksyku)", en: F. Rosiński O.F.M. (ed.), Observare Evangelium. Wroctawska Księga Jubileuszu 800-lecia Zakonu Braci Mniejszych, Wrocław, Franciszkańskie Wydawnictwo św. Antoniego, 2009, pp. 267-294; "Fray Juan de Zumárraga ¿Fanático destructor o benefactor? (Equipaje intelectual y espiritual versus la «leyenda negra» de la evangelización franciscana en 
falta mencionar que lo propuesto por Maravall (savonarolismo), Phelan (milenarismo) y Baudot (milenarismo apocalíptico y mesianismo) fue continuado por muchos autores y casi siempre recurriendo a la misma referencia donde como punto central aparece un fragmento del salmo $59^{11}$.

Ahora bien, lo que llama atención y constituye el objeto de la presente glosa es el hecho de que ninguno de los autores mencionados y -en general - en la bibliografía que sigue aceptando la idea del milenarismo apocalíptico o la que la está criticando no encontramos algo que podríamos denominar como la crítica de la fuente primaria, es decir, de lo que aparece en las crónicas tanto de Motolinía como Mendieta. Lo que nos ocupa aquí puntualmente es la referencia al salmo 59 que aparece de manera bastante similar en ambos autores.

En el caso de Motolinía, primero que nada, tenemos una indicación precisa de qué salmo se está tratando, ya que el autor menciona su primera línea en latín: Eripe me de inimicis meis. Luego Motolinía cita la exclamación de Martín de Valencia, hablando del cumplimiento de una profecía, que seguramente y según su biógrafo éste leía en el salmo mencionado. Motolinía no la cita, en cambio Mendieta complementa el relato de su predecesor, diciendo a propósito del salmo: "donde dos veces se repite aquel verso, Convertentur ad vesperam, et famen patientur ut canes: convertirse han á la tarde, y padecerán hambre como perros" [resaltado mío].

Justamente aquí surgen dudas muy serias. La lectura que prevalece tanto de la versión latina ${ }^{12}$ como de la versión hebrea ${ }^{13}$ es siguiente: "Vuelven al

la evangelización franciscana en la Nueva España)", Estudios Latinoamericanos, 28, 2008, pp. $135-183$.

${ }^{11}$ Cf. M. A. Segundo Guzmán, "El descubrimiento de América en la última hora del mundo: la hermenéutica franciscana", Nuevo Mundo Mundos Nuevos, Débats, $<\mathrm{http} / /$ nuevomundo.revues. org/63661> 20 de septiembre 2015; DOI : 10.4000/nuevomundo.63661; A. Val O.F.M., "El milenarismo en la primera evangelización de los franciscanos en América", en: J. I. Duarte de la Iglesia (coord.), Milenarismos y milenaristas en la Europa medieval: IX Semana de Estudios Medievales, Nájera, 1998, Logroño, Instituto de Estudios Riojanos, 1999, pp. 365-382, A. García-Abásolo, "La visión del indio americano en los primeros franciscanos de México", en: J. La Prades, G. Gutiérrez López (coords.), Ciencias Humanas y Sociedad, Fundación Oriol-Urquijo, Madrid, Ediciones Encuentro, 1993, pp. 191-197; L. Weckmann, "Las esperanzas milenaristas de los franciscanos de la Nueva España”, en: Historia Mexicana, vol. 32, n 1 (Jul.-Sep. 1982), México D.F., El Colegio de México, pp. 89-105.

${ }^{12}$ Al respecto nos permitimos hacer una consulta al profesor Jakub Pigoń, jefe del Departamento de Filología Latina de la Universidad de Wroclaw (en octubre de 2015), quien nos aseguró que la lectura del verbo latino en cuestión debe ser traducida (en infinitivo) como "volver o regresar", aunque nos informó que en el pasado y debido a diferentes razones, las traducciones no necesariamente eran muy fieles respecto al original.

13 Aquí debemos nuestros grandes agradecimientos al Dr. Krzysztof Morta, subjefe de la Escuela de las Lenguas Antiguas y Orientales, jefe del Taller del Antiguo Cercano Oriente y de la Tradición Bíblica y Director del Centro de Estudios sobre la Historia y Cultura de los Judíos de la Gran Polonia Meridional. Acudimos a sus competencias al respecto (consulta hecha a través del correo electrónico en diciembre de 2015) y recibimos la siguiente lectura del fragmento en

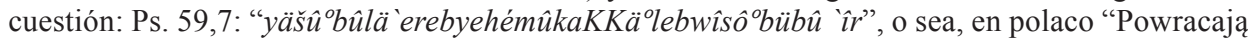


atardecer | ladrando como perros, | merodean por la ciudad"14. Es interesante observar que en el portal Biblegateway encontramos 17 diferentes versiones de las Sagradas Escrituras y en todas lo de "convertentur" aparece traducido como "vuelven" o "regresan"15.

Ahora bien, en el portal del Corpus de la Biblia Medieval ${ }^{16}$ encontramos siete fuentes de las versiones en castellano de las Sagradas escrituras con el fragmento del salmo 59 que constituye aquí el objeto de nuestra reflexión. De estas siete fuentes dos presentan una interpretación prácticamente igual a la de Mendieta. A continuación, presentamos estas siete versiones, colocando en notas a pie de página datos pormenorizados respecto a cada una de las fuentes mencionadas ${ }^{17}$.

Hay que observar que los dos casos donde aparece el verbo "convertir" (GE y E4 ${ }^{7}$ ) corresponden a las traducciones del latín al castellano. Parece que no haya posibilidad ninguna para deducir por qué los autores de estas traducciones recurrieron a un verbo que a todas luces no tiene nada que ver con el original ${ }^{18}$. Para reforzar esta aseveración vamos a consultar la obra de Alonso Schökel, una de las personas más importantes de la teología, estudios bíblicos y de la hermenéutica española, obra compartida con Cecilia Carniti ${ }^{19}$. Obviamente, las traducciones presentes en esta obra fueron hechas del hebreo. El fragmento que nos ocupa aquí tiene la siguiente versión en castellano: "Vuelven al atardecer, aullando como perros, merodean por la ciudad"20. Para averiguar si nuestra hipótesis de que lo mencionado por Motolinía y Mendieta es una interpretación o traducción demasiado forzada y errónea tenemos que analizar la comparación hecha en el salmo 59 de los perseguidores del sujeto lírico con los perros. En la versión polaca de las Sagradas Escrituras ${ }^{21}$ encon-

wieczorem, warczą jak pies i krążą po mieście". Es decir, en castellano: "Vuelven por la tarde, gruñen como perro y recorren la ciudad".

${ }^{14}$ Es la versión de Sagrada Biblia de la Conferencia Episcopal Española (a continuación SBCEE), p. 661: <http://juanstraubinger.blogspot.com/2015/05/biblia-de-la-conferencia-episcopal. html> 3 de abril 2016.

15 A título de ejemplo: Regresan al anochecer, aúllan como perros - La Biblia de las Américas (LBLA); Se volverán a la tarde, ladrarán como perros - Jubilee Bible 2000 (Spanish) (JBS); Se volverán a la tarde, ladrarán como perros - Nueva versión internacional (Castilian) (CST) $<$ https:// www.biblegateway.com> 5 de abril de 2016.

${ }^{16}$ A. Enrique-Arias, F. J. Pueyo Mena, Biblia Medieval, 2008-, $<$ http://corpus.bibliamedieval. es> $5-8$ abril de 2016.

17 Todas los resaltados de la tabla son míos.

${ }^{18}$ Es interesante que cuando en el verso 15 tiene que repetirse la frase del verso 7 aquí aparece un texto distinto: "Quebrantados seran ala | tarde \& aueran fanbre commo el perros". Lo que muestra, quizás cierta inseguridad del autor de la traducción... Manuscrito E4, $<$ http://corpus. bibliamedieval.es/> p. 59, v. 15 .

19 A. Schökel, C. Carniti, SALMOS I (Salmos 1-72) Traducción, introducciones y comentario, Estella (Navarra), Editorial Verbo Divino, 1992, pp. 786-795, <http://www.mercaba.org/mediafire/ alonso\%20schoekel,\%20luis\%20-\%20salmos\%2001-72.pdf> febrero-abril 2016.

${ }^{20}$ Ibidem, p. 787 (en cursiva ponen los autores fragmentos repetitivos; doble estribillo); se acepta también, en lugar de "aullar", verbo 'gruñir', p. 788.

${ }^{21}$ Pismo Święte Starego i Nowego Testamentu, Poznań, Pallotinum, 2012, p. 715. 


\begin{tabular}{|c|c|}
\hline 武 & 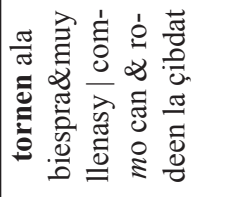 \\
\hline$\sum_{\infty}$ & 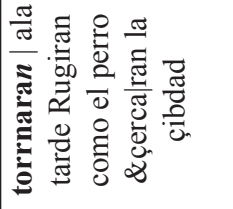 \\
\hline 芒 & 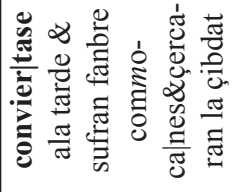 \\
\hline$\stackrel{8}{3}$ & 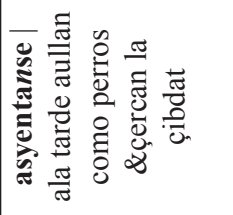 \\
\hline$\underset{\text { 至 }}{\stackrel{+}{N}}$ &  \\
\hline 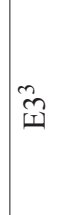 & 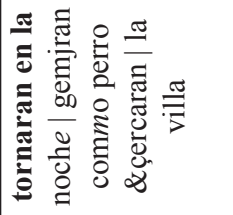 \\
\hline$\sqrt{0}$ & 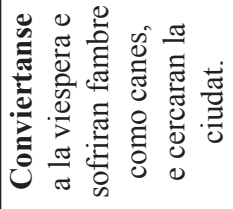 \\
\hline $\begin{array}{l}\overrightarrow{0} \\
\text { İ } \\
\infty \\
\text { II }\end{array}$ & 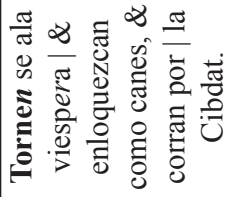 \\
\hline
\end{tabular}

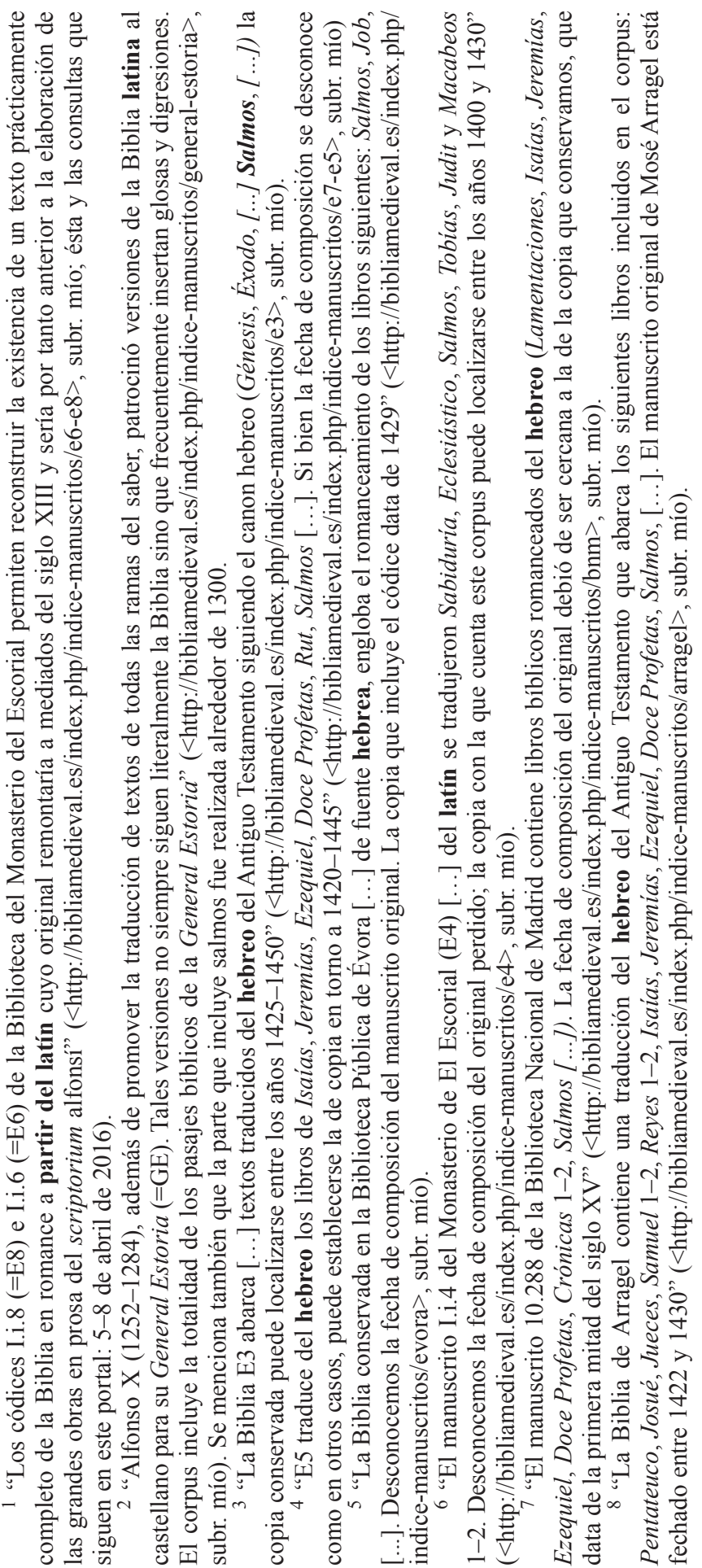


tramos una observación importante sobre el uso del término "perros": "Perros son una plaga esencial de las ciudades del Cercano Oriente. El uso de dos veces de la comparación de los enemigos con perros subraya sus incesantes intentos, llenos de odio y de la ansiedad de ganancia". En el libro mencionado de Schökel i Carniti encontramos una característica más desarrollada aún y muy interesante desde el punto de vista del problema traductológico que nos ocupa en esta glosa:

Los perros todavía no se consideraban animal doméstico "el mejor amigo del hombre". Son perros salvajes, peligrosos, famélicos; probablemente habitan en descampado y acceden a la morada del hombre para apagar el hambre con sus sobras. Su boca babea [...], en ella asoman colmillos relucientes como puñales, su aullido suena a amenaza. No han comido durante el día, y al atardecer acuden en busca de comida. [...] Los perros se cuelan antes de que las puertas de la ciudad se cierren, y no es fácil expulsarlos. [...] Esos perros [...] son hombres ávidos, despiadados. La imaginación puede sugerirnos correspondencias parciales: hambre insaciable es su codicia, baba es su lenguaje soez, quizás sean verdaderos sus puñales. El v. 13 habla de insolencia, maldición y fraude. En otros versos aparecen como enemigos, agresores, malhechores, sanguinarios, crueles, traidores...22

Las dos citas recién mencionadas nos presentan una imagen de los perseguidores del sujeto lírico del salmo que difícilmente encaja en las características eventuales de unos conversos, que más encima no tendrían por qué — una vez convertidos- seguir gruñendo, aullando, ladrando (lo que sea...) y junto con este espantoso ruido también seguir recorriendo la ciudad. Hay aquí también otro problema, pues los que se compara con los perros aparecen en la versión hebrea ${ }^{23}$ como "pueblo", aunque se aplica "en oposición a Israel" paganos (gentiles). En la traducción propuesta por Schökel y Carniti aparece la palabra "paganos" (59 $6,9)$ y en las fuentes indicadas en la tabla tenemos: gens (E8/E6), gentes (GE, E4, ARRAGEL), gentíos (E3, E5/E7, EV, BNM); agreguemos que la lección de Schökel y Carniti es la única, ya que en el resto de las traducciones contemporáneas encontramos el término "naciones" 24.

Ahora bien, independientemente de lo que hemos presentado hasta el momento, lo que nos muestra hartas dudas respecto a la interpretación o traducción del verso 7 y 15 del Salmo 59 hecha primero por Motolinía y luego por

22 A. Schökel, C. Carniti, op. cit., p. 789.

${ }^{23}$ Seguimos en este ámbito con la consulta y ayuda que gentilmente nos prestó Dr. Morta.

${ }^{24}$ Sabemos que en cuanto los versos 6 y 9 en Séptuaginta aparce el concepto "ethnos". Hemos consultado al respecto también Libro de Salmos de la Bahía (Bay Psalm Book), el primer libro publicado en las colonias inglesas de América del Norte. Su primera edición, impresa en 1640, contiene los Salmos traducidos del hebreo al inglés que se hablaba en aquellos tiempos. En el salmo 59 aparece el término heathens [paganos] donde en la versión latina tenemos gentes, y en la española (excepto Schökel y Carniti) aparecen naciones. Mencionemos de paso que en las traducciones polacas aparecen tanto naciones/pueblos o paganos. El fragmento que nos interesa figura en el Libro de Salmos de Bahía de siguiente forma: "At evning they returne, \& like To dogs a noyfe doe make"; The Whole Booke of Psalmes; 1640, < http://www.wdl.org/es/item/2834/view/1/63/ /64> 16 de octubre de 2015. 
Mendieta, tenemos que agregar unas observaciones provenientes de la ya citada obra de Schökel y Carniti. Al final de la parte dedicada al Salmo mencionado, los autores colocan un punto intitulado "Transposición cristiana". Se trata de cómo los Padres de la Iglesia absorbieron el contenido del salmo para el mensaje evangélico, particularmente "en la coyuntura de la pasión" 25 de Cristo. Aquí tenemos dos cosas:

1. Respecto al verso $14^{26}$ : "Para armonizar el v. 14 , recurren algunos a una precisión. Eusebio lo declara «profecía, no imprecación»; Teodoreto explica que dejan de existir como pueblo, pero que no se habla de la condenación de las almas, y Agustín dice que no persistirán en su arrogancia"27.

2. Tomando $p q d$ en sentido de visitar, refieren el v. 6 a la elección y conversión de los paganos" 28 .

De esta manera, el original verso 14 se podría interpretar, a la luz del contenido del Nuevo Testamento, como mensaje profético del inevitable reconocimiento del verdadero Dios en mundo entero ${ }^{29}$, lo que unido con Mt $24,14^{30}$ podría eventualmente asomarse a una remota idea del milenarismo apocalíptico, aunque siempre hay que recordar la tajante aseveración del Mt 24, $36^{31}$. Tal vez, lo que leemos en la crónica de Motolinía guarda relación justamente con este verso, aunque habría que preguntarnos si en su tiempo ya existían suficientes instrumentos de la hermenéutica bíblica para que hubiera sido corriente, entre los religiosos también, una interpretación similar y a la vez tan rebuscada.

Veamos ahora el verso 6: “¡Despierta, ven a mi encuentro, mira, tú, Señor Dios de los Ejércitos, Dios de Israel! Levántate y castiga a los paganos, no tengas piedad de los traidores inicuos"32. Para tratar de comprender mejor aquella aseveración bastante escueta de Schökel y Carniti (punto 2) hemos recurrido al Diccionario Teológico Manual del Antiguo Testamento para aclarar las eventuales acepciones teológicas del verbo $p q d^{33}$. Por cierto, las aclaraciones en

${ }^{25}$ A. Schökel, C. Carniti, op. cit., p. 795.

${ }^{26}$ Ibidem. "Acaba con ellos con ira, acaba con ellos, que dejen de existir; y sabrán que Dios gobierna en Jacob y hasta los extremos del orbe".

27 Ibidem, subr. mío.

${ }^{28}$ Ibidem, subr. mío.

${ }^{29}$ Cf. SBCEE, ed. cit., p. 661: “iDestrúyelos con tu furor, | destrúyelos y dejen de existir! | Sepan que Dios gobierna $\mid$ desde Jacob hasta los confines de la tierra".

30 "Y se anunciará el evangelio del reino en todo el mundo como testimonio para todas las gentes, y entonces vendrá el fin". SBCEE, ed. cit., p. 1135.

31 Ibidem.

${ }^{32}$ A. Schökel, C. Carniti, op. cit., p. 787, subr. mío; cf. SBCEE, p. 661: “| Despierta, ven a mi encuentro, mira: tú, el Señor del universo, | el Dios de Israel. | Despierta para castigar a los gentiles, | no te apiades de los traidores inicuos". (es fragmento del v. 5 más v. 6. es decir lo que en Schökel aparece todo en el verso 6); cf. también: <https:/www.biblegateway.com/passage/?version=RVA\&search=Salmos\%2059> 8 de abril de 2016: "Y tú, Jehová Dios de los ejércitos, Dios de Israel, Despierta para visitar todas las gentes: No hayas misericordia de todos los que se rebelan con iniquidad" (subr. mío).

33 J. Ernst (ed.), C. Westermann (colab.), Diccionario Teológico Manual del Antiguo Testamento, Madrid, Ediciones Cristianidad, 1985, pp. 589-611. 
este caso, extremadamente competentes abarcan 11 páginas (en dos columnas con su respectiva numeración), por lo tanto nos vamos a referir solamente a estos fragmentos que guardan relación directa con el Salmo 59 o aquellos que esclarecen nuestro problema más aún en contextos distintos. En términos generales se observa que el significado básico de la raíz pqd es controvertido. Se consideran como posibles "echar de menos, preocuparse de" o "mirar o cuidar de algo con preocupación o interés" (590), pero también "mantener vigilancia, preocuparse intensamente de algo, efectuar un control detallado" o "supervisar a alguien/algo, controlar, vigilar" además "buscar (visitar)" y "disponer" (591). Igual también se indica que en hebreo existe "una considerable amplitud de significado" (594). En el Diccionario se menciona que respecto al lenguaje teológico en el Viejo Testamento el significado del verbo en cuestión se traduce como "ver atentamente o examinar a alguien/algo"; "buscar, visitar para ver a alguien/algo". Se indica también una interesante referencia interpretativa respecto al Salmo 80, 15-16: "Dios del universo, vuélvete: | mira desde el cielo, fíjate, | ven a visitar tu viña. Cuida la cepa que tu diestra plantó | y al hijo del hombre que tú has fortalecido"34. Lo que según el Diccionario Teológico y en el contexto del contenido completo del salmo citado "[...] se emplea para la búsqueda emprendida por un pastor de las ovejas perdidas de su rebaño para el registro de la propia vivienda y del propio entorno" (601). También se indica en el Diccionario citado que en el Viejo Testamento "uso teológico de $p q d$, como concepto que expresa el interés salvador del Yahvé por el individuo o por Israel como pueblo, en el sentido de «cuidar atentamente de, prestar atención o mirar por, interesarse por alguien [...] [sentido que] aparece ya en relatos antiguos»" (601, subr. J.A.) El verbo en cuestión se usa también "en la ayuda que encuentra el pueblo en un peligro determinado" (ídem) y en la forma de súplica (602): "Acuérdate de mí | por amor a tu pueblo, | visítame con tu salvación" (Sal 106, 4, subr. J.A.) ${ }^{35}$. Se agrega además que en el lenguaje del Viejo Testamento “[...] está mucho más extendido el uso $p q d$, «visitar», en el sentido de una intervención de Yahvé para pedir cuentas por las faltas y omisiones" (603, subr. J.A.). Las interpretaciones más relevantes aún para nosotros aparecen en la siguiente columna donde se afirma que "Sin embargo, son más frecuentes los textos en los que las explicaciones y conceptos de $p q d$ establecen el sentido de una intervención punitiva de Yahvé contra los pecados y contra los que los han cometido" (604). Finalmente (608) tenemos una conclusión interesante para nuestro tema: “[...] en cuanto el lenguaje de la profecía exílicoposexílica [...] en la que la amenaza del castigo de Yahvé se dirige siempre a los pueblos extranjeros y a sus soberanos [...]"; cf. también el grito de súplica del Sal 59, 6: "despierta para castigar a todos los pueblos" (608).

Ahora bien, volviendo al punto 2, donde — siguiendo a Schökel y Carniti- mencionamos la posibilidad de interpretar el pqd como "la elec-

\footnotetext{
${ }^{34}$ SBCEE, op. cit., p. 675.

35 Ibidem, p. 690.
} 
ción y conversión de los paganos", interpretación que encuentran los autores citados en la transposición cristiana del Salmo 59, hecha por los Padres de la Iglesia. Lamentablemente no se pone en este caso ninguna referencia bibliográfica. Por lo tanto, las expresiones del castigo, y ajuste de cuentas vinculados quizás con el interés salvífico de Dios resultan por el momento las más convincentes y - en términos generales - se asemejan un poco al trasfondo del anhelo supuestamente expresado por Marín de Valencia, trasfondo no precisado por Motolinía, quien indica solamente el Salmo 59 y nada más, y -a su vez - trasfondo precisado en forma errónea por Mendieta, quien, como ya hemos dicho, forzando la traducción del latín del verso 7 insiste de que éste era el verso profético que tenía Martin de Valencia, cuando expresaba su exclamación.

El análisis que hemos realizado en esta glosa tuvo como su propósito poner de manifiesto la relevancia de la crítica de fuentes, antes de plantear diferentes ideas sobre la base de una $u$ otra fuente no revisada, analizada y por cierto correctamente interpretada. En nuestro caso, dos fragmentos - sin mencionar otras referencias- de las crónicas del siglo XVI han impulsado a la creación de toda una teoría sobre el equipaje espiritual y teológico de los primeros franciscanos que iniciaron a partir de los años 1523-1524 la misión evangelizadora en Nueva España. Una teoría que tomando en cuenta solamente lo que hemos expuesto aquí resulta bastante dudosa ${ }^{36}$.

${ }^{36}$ Entre los más duros críticos del supuesto equipaje apocalíptico milenarista de la fundadora misión franciscana en México (1523-1569), encontramos a Lino Canedo ("Milenarismo, escatología y utopía en la evangelización de América", en: J. Saranyana et al. (eds.), op. cit., vol. 2, p. 1399) quien al mencionar a Phelan, Baudot y Maravall dice: "Las obras de los dos primeros contienen [...] afirmaciones apodícticas, reiterativas y rotundas, que al parecer son aceptadas por algunos americanistas, mientras a otros nos parecen muy discutibles y aun del todo rechazables. Por mi parte, como asiduo lector de los escritos de Motolinía y Mendieta — en los que se pretende fundamentar dichas teorías - no encuentro base alguna firme para atribuirles tales esperanzas escatológicas - fuera de las legítimas de todo cristiano-y mucho menos de un reino milenario". Otro autor digno de mencionar es Melquiades Andrés Martín quien opina (op. cit. p. 375) que los Doce "Han salido de Europa en la hora undécima, cuando declina en ella el sol de la cristianidad y en América está germinando un mundo nuevo. Llevan a aquellas tierras la descalcez, que es la cima de la reforma española, después de un siglo largo de ensayos. No cuentan para evangelizar con métodos heredados y experimentados. Quiñones les ha señalado la vía del evangelio y de la regla" (subr. mío). Finalmente leemos la conclusión de Martín (p. 388): "El estudio de la espiritualidad franciscana como humildad, pobreza y vivencia del misterio de la cruz llega mucho más a las raíces que otras que hablan de una «espiritualidad profética, impregnada por las perspectivas escatológicas del joaquinismo basadas en el milenarismo»". 


\section{Referencias bibliográficas}

\section{ACHMATOWICZ J.}

2009 "Dwunastu ewangelizatorów Nowej Hiszpanii (przyczynek do historii duchowego podboju Meksyku)", en: Rosiński F. O.F.M. (ed.), Observare Evangelium; Wrocławska Księga Jubileuszu 800-lecia Zakonu Braci Mniejszych, Wrocław, Franciszkańskie Wydawnictwo św. Antoniego, pp. 267-294.

2009 "Fray Juan de Zumárraga ¿Fanático destructor o benefactor? (Equipaje intelectual y espiritual versus la «leyenda negra» de la evangelización franciscana en la evangelización franciscana en la Nueva España)", Estudios Latinoamericanos, 28, pp. 135-183.

ANDRÉS MARTÍN M.

1986 "La espiritualidad de los «Doce» en Extremadura y en Nueva España", en: Congreso franciscanos extremeños en el Nuevo Mundo. Actas y Estudios, Monasterio de Santa María de Guadalupe, pp. 367-432.

1990 "En torno de las últimas interpretaciones de la primitiva acción evangelizadora en México", en: Saranyana J., Tineo P., Pazos A., Lluch-Baixaulli M., Ferrer M.P. (eds.), Evangelización y teología en América (siglo XVI): X Simposio Internacional de Teología de la Universidad de Navarra, Servicio de Publicaciones de la Universidad de Navarra, vol. 2, pp. 1345-1370.

BAUDOT G.

1983 Utopía e Historia en México, Madrid, Espasa-Calpe.

1996 "Las crónicas etnográficas de los evangelizadores franciscanos", en: Garza Cuarón, B., Baudot, G., Historia de la literatura mexicana, México, D.F., Siglo XXI, pp. 287-320.

BIBLEGATEWAY

$<$ https://www.biblegateway.com> 5-8 de abril de 2016.

BIBLIA DEL OSO

$1569<\mathrm{https} / / /$ www.originalbibles.com/biblia-del-oso-bible-in-spanish-1569-pdf/ $>7 \mathrm{de}$ abril de 2016.

CANEDO L.L.

1989 "Milenarismo, escatología y utopía en la evangelización de América", en: 10 Simposio Internacional de Teología de la Universidad de Navarra, tomo II, Pamplona, pp. 13991409.

CHAUVET F.

1983 Franciscanos memorables en México, México, Centro de Estudios Bernardino de Sahagún.

ENRIQUE-ARIAS A., PUEYO MENA F.J.

2008-Biblia Medieval, <http://corpus.bibliamedieval.es> 5-8 abril de 2016.

ERNST J. (ed.), WESTERMANN (colab.)

1985 Diccionario Teológico Manual del Antiguo Testamento, Madrid, Ediciones Cristianidad.

FROST C.

1996 Este nuevo orbe, México D.F., UNAM, Serie Nuestra América 52.

GARCÍA-ABÁSOLO A.

1993 "La visión del indio americano en los primeros franciscanos de México", en: Prades J., Gutiérrez López G. (coords.), Ciencias Humanas y Sociedad, Fundación Oriol-Urquijo, Madrid, Ediciones Encuentro, pp. 191-197.

KOBAYASHI J.M.

2002 La educación como conquista, México D.F., El Colegio de México.

LEÓN-PORTILLA M.

1999 Fray Bernardino de Sahagún pionero de antropología, México D.F., UNAM.

MARAVALL J.A.

1982 "La utopía político-religiosa de los franciscanos en Nueva España", en: La utopía y reformismo en la España de los Austrias, Madrid, Siglo XXI de España Editores, 1982, pp. 
79-110. Artículo originalmente publicado en: Revista de Estudios Americanos, $\mathrm{n}^{\mathrm{o}}$ 2, Sevilla, 1949, pp. 199-227.

\section{MENDIETA J.}

1993 [1870] Historia Eclesiástica Indiana, México D. F., Editorial Porrúa.

MOTOLINIA BENAVENTE T.

2004 [1858-1866] "Historia de los indios de la Nueva España", en: García Icazbalceta J., Colección de documentos para la historia de México, t. I, México, Editorial Porrúa.

\section{PHELAN J.L.}

1972 El reino milenario de los franciscanos en el Nuevo Mundo, México D.F., UNAM. PISMO ŚWIĘTE

2012 Pismo Święte Starego i Nowego Testamentu, Poznań, Pallotinum.

PSALMES

1640 The Whole Booke of Psalmes, <http://www.wdl.org/es/item/2834/view/1/63//64> 16 de octubre de 2015.

SAGRADA BIBLIA

Sagrada Biblia de la Conferencia Episcopal Española, $<\mathrm{http} / /$ juanstraubinger.blogspot. com/2015/05/ biblia-de-la-conferencia-episcopal.html> 3 de abril 2016.

SCHÖKEL A., CARNITI C.

1992 SALMOS I (Salmos 1-72). Traducción, introducciones y comentario, Estella (Navarra), Editorial Verbo Divino, pp. 786-795, <http://www.mercaba.org/mediafire/alonso\%20 schoekel,\%20luis\%20-\%20salmos\%2001-72.pdf> febrero-abril 2016.

SEGUNDO GUZMÁN M. A.

2012 "El descubrimiento de América en la última hora del mundo: la hermenéutica franciscana", Nuevo Mundo Mundos Nuevos [En ligne], Débats, < http://nuevomundo.revues. org/63661> 20 de septiembre 2015; DOI: 10.4000/nuevomundo.63661.

VAL A. O.F.M.

1999 "El milenarismo en la primera evangelización de los franciscanos en América", en: Duarte de la Iglesia J. I. (coord.), Milenarismos y milenaristas en la Europa medieval: IX Semana de Estudios Medievales, Nájera, 1998, Logroño, Instituto de Estudios Riojanos, pp. 365-382.

WECKMANN L.

1982 "Las esperanzas milenaristas de los franciscanos de la Nueva España", en: Historia Mexicana, Vol. 32, No 1 (Jul.- Sep., 1982), México D.F., El Colegio de México, pp. 89-105.

\section{Psalm 59 as the basis of apocalyptic-millenaries interpretation of in New Spain Franciscans the founder's mission}

Keywords: Psalm 59 - Franciscans — evangelization — apocalyptic millenarianism.

\section{Abstract}

Article treat about the criticism of sources. In this case it comes to appeal to the Spanish chroniclers Motolinii and Mendieta to Psalm 59. In Mendieta comes to special translate a fragment of the same psalm, which is one of the foundations of apocalyptic-millenaries interpretation of the Franciscan missions in Mexico in the first half of the sixteenth century.

Using specific translating tools we show that the said base includes acceptance of confusion mentioned Psalm, which allows us to identify the specific validity of source criticism. It should be mentioned that the analysis of a fragment of Psalm 59, which in this context is the first to carry out 
the extensive literature on the subject, both when it comes to apocalyptic-millenaries perception of Franciscan spirituality among the missionaries operating in New Spain (including Phelan, Baudot) as well as the critics of such perception (Lino Canedo, Andrés Martín, Zaballa Beascoechea). 